\title{
Chemical Studies of Traffic Generated Dust and its Impact on Human Health with Associated Problems in Singrauli District of Madhya Pradesh, India
}

\author{
VINOD KUMAR DUBEY ${ }^{1}$, DHANANJAI SINGH ${ }^{2}$ and NEHA SINGH ${ }^{3}$ \\ 'Department of Chemistry, SGS Govt. P.G. Autonomous \\ (NAAC Accredited) College, SIDHI-486661 (M.P.) India. \\ ${ }^{2}$ SMS (Agronomy) Krishi Vigyan Kendra, SIDHI-486661 (M.P.) India. \\ ${ }^{3}$ Applied Chemistry Division, Department of Chemistry, SGS Govt. P.G. \\ Autonomous (NAAC Accredited) College, SIDHI-486661 (M.P.) India.
}

http://dx.doi.org/10.12944/CWE.8.3.15

(Received: November 19, 2013; Accepted: December 05, 2013)

\begin{abstract}
The traffic generated dust now become a problem for urban people. Rate of dust fall in urban areas of Singrauli was estimated during two consecutive years (2011 and 2012) through recommended methods. The levels of dust fall in Singrauli during both years remained the highest (37.56 and $41.32 \mathrm{~g} / \mathrm{m}^{2} / \mathrm{month}$ ) respectively, with high traffic density. Among the locations, Waidhan showed with the highest rate of dust fall while Shakti nagar showed the lowest. Metallic analysis of dust fall in Singrauli was made through atomic absorption spectrophotometer. All the investigated metals except $\mathrm{Ni}$ were found high in all the dust fall samples of all the location and dust sample collected during 2012 showed high content of heavy metals than 2011. Data regarding impact of air pollution on human health exhibited that the percentage of pulmonary disease, eye irritation and headache in the urban area of Singrauli was found the highest than any other and $55 \%$ of effected people were those who practiced trade while being directly exposed to the pollutant without any protective measures.
\end{abstract}

Key words : Singrauli, Dust fall, Heavy metals, Traffic Density, Human Health.

\section{INTRODUCTION}

Certainly dust deteriorates the ecological condition and can be defined as the fluctuation in any atmospheric constituent from the value that would have existed without human activity (Tripathi and Gautam, 2007). Environmental degradation exerts significant pressure on human health; unfortunately these aspects are closely associated with the hazards to the environment and human caused by transport specially road transport (Dora and Phillips, 2000). The impact of dust pollution on health and the economy have resulted in measures to mitigate emissions of the most harmful pollutants such as particle pollution (acids, organic chemicals, metals and soil/dust particles) and ozone which affects the respiratory system. Despite national and international interventions and decreases in major pollutant emissions the health impact of air pollution are not likely to decrease in years ahead unless appropriate action is taken. Health problems linked to air pollution ranges from minor eye irritation to upper respiratory symptoms, chronic respiratory diseases such as asthma, cardiovascular diseases and lung cancer. The atmospheric dust loading has been increasing over the last years due to global warming, increasing desertification and human activities (Derbyshire, 2007). The dust pollution affects not only environmental but also affects biogeochemical cycles of the earth (Tegen, 2006).

The study area (Singrauli) is located in the mountainous region of Singrauli district surrounding in North Sonbhadra district of Uttar 
Pradesh and in south Chhatishgarh and east Chhatishgrah and west Sidhi district of M.P. Most emerging industrial capital of Madhya Pradesh state of India. It lies approximately $24^{\circ} 11^{\prime}$ 59" North latitude and $82^{\circ} 40^{\prime} 31^{\prime \prime}$ East longitude and 365 meters elevation above the sea level. The present municipal corporation area limits approximately 22 $\mathrm{Km}^{2}$. populations about 2 lakh. There is number of Asia's big coal mines, thermal power generating unit in public/private sectors both and number of associated minor and major industries based on coal run by Govt. and private basis and hence people activity in road transport specially also increasing day by day and resulting into dust pollution.

\section{MATERIAL AND METHODS}

\section{Dust fall collection and metallic anyaliss}

Dust fall measurement was carried out for two complete years (2011 and 2012) by recommended standard method (Robert, 1986). Dust fall containers/collectors of standard size and shape i.e. 20-22 cm. mouth diameter Jars, $16 \mathrm{~cm}$ base diameter and $25 \mathrm{~cm}$. height were used and heavy traffic road were chosen for the sampling. Dust fall containers were installed at five locations on Morba chauk near bus stop, near Shakti Nagar Chauk, Waidhan market Chauraha, Waidhan Vindhya Nagar road near bus stop and Mahajan turning point.

After a period of one calendar month, the collectors were taken off, covered with plastic lid and brought to the laboratory analysis (Farid et. al., 2002), the sample were analyzed for heavy metals through atomic absorption spectrophotometer (model 2380 Perkin Elmer).

\section{Traffic counting}

The Vehicles passing along the selected road were collectors for 12 peak hours form 8 AM to $8 \mathrm{PM}$ for three consecutive days of every month and average was taken form 10 busiest road of the Singrauli Municipal area for the period of two years i.e. 2011-2012. In traffic counting, buses, trucks, wagons, cars, motorbikes, autorickshaws, were counted separately (Khan, 1996, Hamidullah et al. 1998).

\section{Impact on Human Health}

For determining the impact of dust pollutants on human, a questionnaire was prepared and distributed among those who were directly

Table 1: Average rate of dust fall ( $\mathrm{g} / \mathrm{m} 2 / \mathrm{month})$ during two consecutive years on different Location at Singrauli

\begin{tabular}{|c|c|c|c|c|c|}
\hline \multirow{2}{*}{$\begin{array}{l}\text { S. } \\
\text { No. }\end{array}$} & \multirow[b]{2}{*}{ Location } & \multicolumn{2}{|c|}{ Total dust fall in 2011} & \multicolumn{2}{|c|}{ Total dust fall in 2012} \\
\hline & & Average & $\begin{array}{l}\text { Standard } \\
\text { Deviation }\end{array}$ & Average & $\begin{array}{l}\text { Standard } \\
\text { Deviation }\end{array}$ \\
\hline 1. & Near Waidhan Bus stop & 45.28 & 0.32 & 48.76 & 1.78 \\
\hline 2. & Morba Chauk Bus stop & 44.66 & 0.28 & 46.89 & 1.82 \\
\hline 3. & Waidhan Market Road & 41.73 & 0.67 & 45.18 & 1.85 \\
\hline 4. & Shakti Nager road & 35.22 & 0.43 & 38.35 & 1.46 \\
\hline
\end{tabular}

Table 2: Average content of heavy metals $(\mathrm{mg} / \mathrm{g})$ in dust fall collected from Singrauli

\begin{tabular}{|c|c|c|c|c|c|c|c|c|c|c|}
\hline No. Location & \multicolumn{2}{|c|}{ Mn/S.D.* } & \multicolumn{2}{|c|}{ Cu/S.D. } & \multicolumn{2}{|c|}{ Pb/S.D. } & \multicolumn{2}{|c|}{ Ni/S.D. } & \multicolumn{2}{|c|}{ Zn/S.D. } \\
\hline 1. Near Waidhan bus stop & 10.9 & 1.1 & 2.8 & 0.1 & 6.9 & 0.2 & 2.3 & 0.1 & 11.2 & 0.1 \\
\hline 2. Morba Chauk bus stop & 12.3 & 0.2 & 4.6 & 0.3 & 3.7 & 0.1 & 1.7 & 0.1 & 10.3 & 0.1 \\
\hline 3. Shakti Nager road & 11.3 & 1.3 & 3.2 & 0.4 & 3.4 & 0.4 & 2.6 & 0.0 & 8.8 & 0.4 \\
\hline 4. Waidhan Market Road & 14.7 & 0.5 & 5.7 & 0.1 & 5.8 & 0.7 & 2.2 & 0.3 & 10.5 & 0.0 \\
\hline Total Mean & 12.3 & 0.52 & 4.07 & 0.022 & 4.95 & 0.35 & 2.2 & 0.16 & 10.2 & 0.2 \\
\hline
\end{tabular}

S.D. ${ }^{*}=$ Standard Deviation 
exposed to the pollutants on the selected road using random sampling methods. Data was also collected form different hospitals of Singrauli/Waidhan/Jayant/ Shakti nager/Vindhya nager about different cases registered in different disease categories data was collected on monthly basis and then an average was calculated (data of the male patient was only taken). Dust fall affect not only the air quality of cities but also public health (Harrison et al., 1997). Dust fall can lead to disease such as tonsillitis, allergy, pneumonia, asthma and eye irritation etc. (Chung et al., 2008, De Langueville et al. 2010, and Chung et al., 2003).

\section{Statistical Analysis}

Standard deviation, values of the means, maximum and minimum values were calculated for a comparison of site categories. To determine the significance of the samples, a paired t-test was performed for the comparison of dust fall collected over two year. Relationship among the two variables was assessed, using correlation coefficient and linear relationship (Steel and Torrie, 1980).

\section{RESULT AND DISCUSSION}

Total 48 samples from each sampling station, were collected and studied on monthly basis form January 2011 to December 2012. The annual average rate of dust fall, average traffic density and increasing percentage of dust fall per annum are shown in (table 1) and (fig. 1-5). Heavy metals compositions of dust fall and its impact on human health were shown in (table 2 and 3 ) and fig. 4 and 5.

Table 3: Showing correlation coefficient between data collected from different hospitals and questionnaires about different diseases categories

\begin{tabular}{lccccc}
\hline $\begin{array}{l}\text { Heart } \\
\text { Patient }\end{array}$ & $\begin{array}{c}\text { ENT } \\
\text { Patient }\end{array}$ & $\begin{array}{c}\text { Blood Pressures } \\
\text { Patient }\end{array}$ & $\begin{array}{c}\text { Chest/lung/ } \\
\text { Asthma Patient }\end{array}$ & $\begin{array}{c}\text { Eye irritation } \\
\text { Patient }\end{array}$ & $\begin{array}{c}\text { Headache } \\
\text { Patient }\end{array}$ \\
\hline $0.82^{* * *}$ & $0.71^{* * *}$ & $0.42^{*}$ & $0.69^{* *}$ & $0.35 \mathrm{~ns}$ & $0.56^{* *}$ \\
\hline
\end{tabular}

${ }^{*},{ }^{* *},{ }^{* * *}$, ns $=$ slightly, highly, very high, non significant respectively

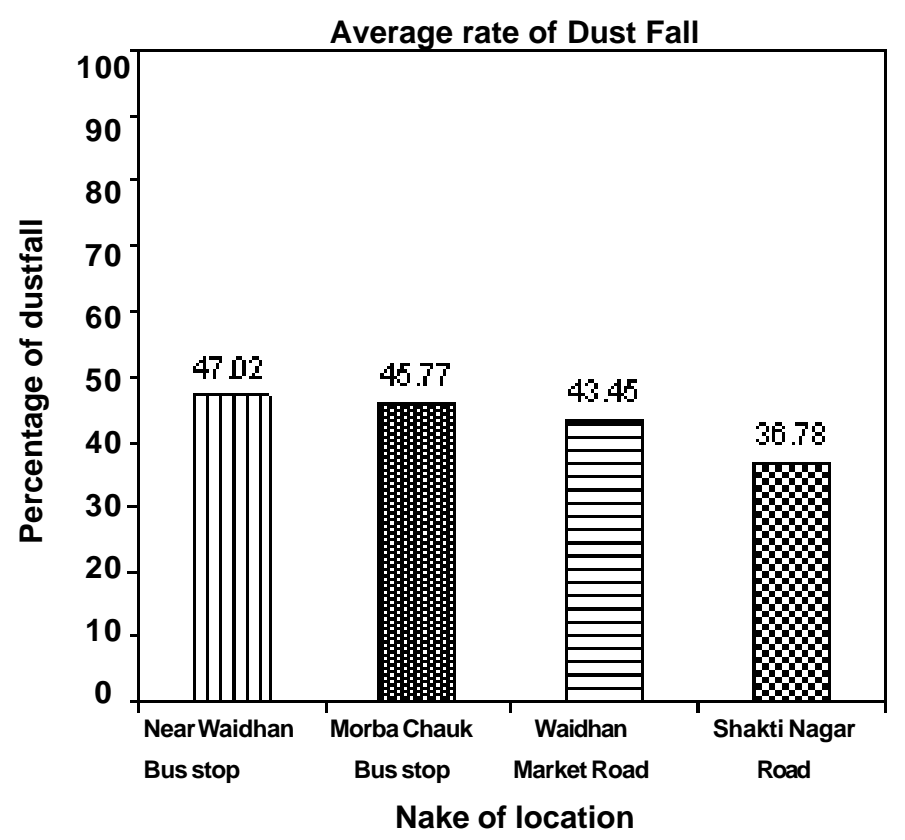

Fig .1: Average rate of dust fall (g/m2/month) on different location of Singrauli during two consecutive years (2011-2012) 


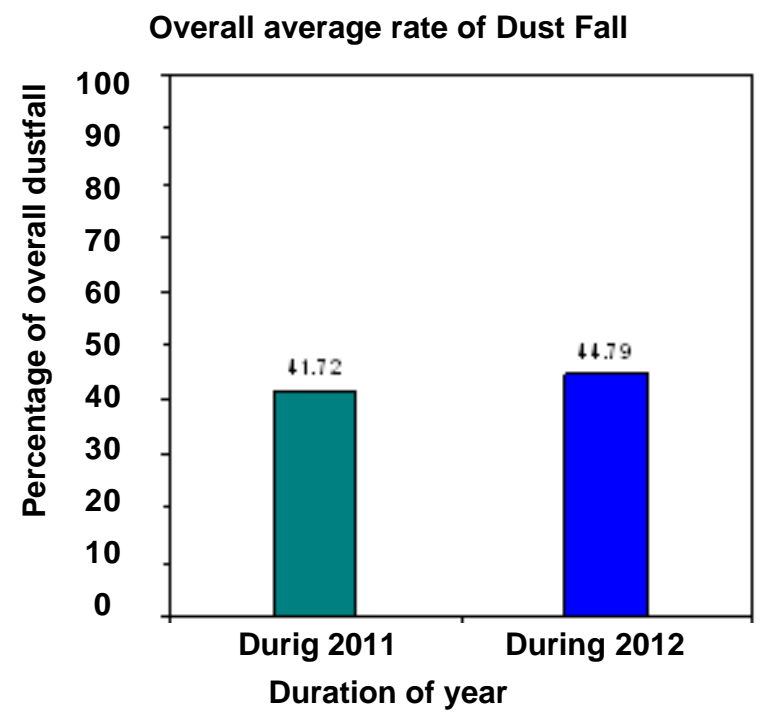

Fig. 2: Overall average rate of dust fall (g/m2/month) on different locations during 2011 and 2012

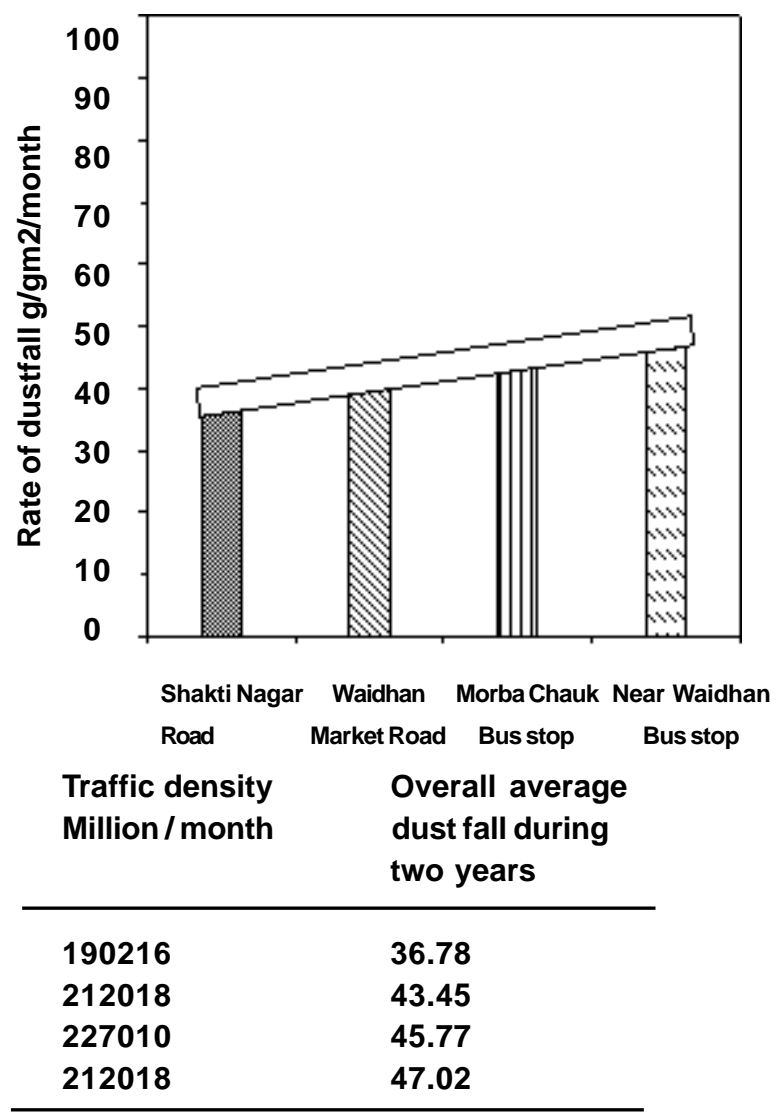

Fig. 3 :Traffic density and dust fall relation 
During 2011 average rate of dust fall (Fine and large particles) was in the range of 35.22-45.28 $\mathrm{g} / \mathrm{m}^{2} / \mathrm{month}$ and during 2012 it changed to 38.35 $48.76 \mathrm{~g} / \mathrm{m}^{2} /$ month with near Waidhan bus stop the largest average rate of dust fall and Shakti nagar road showing the least.
Statistical analysis using t-test indicated that all the locations showed significant $(P<0.001)$ high rate of dust fall during 2012 than 2011 (table 1). Overall average rate of dust fall on different locations of the city Singrauli during both years was found $36.78-47.02 \mathrm{~g} / \mathrm{m}^{2} / \mathrm{month}$ lowest to highest respectively.

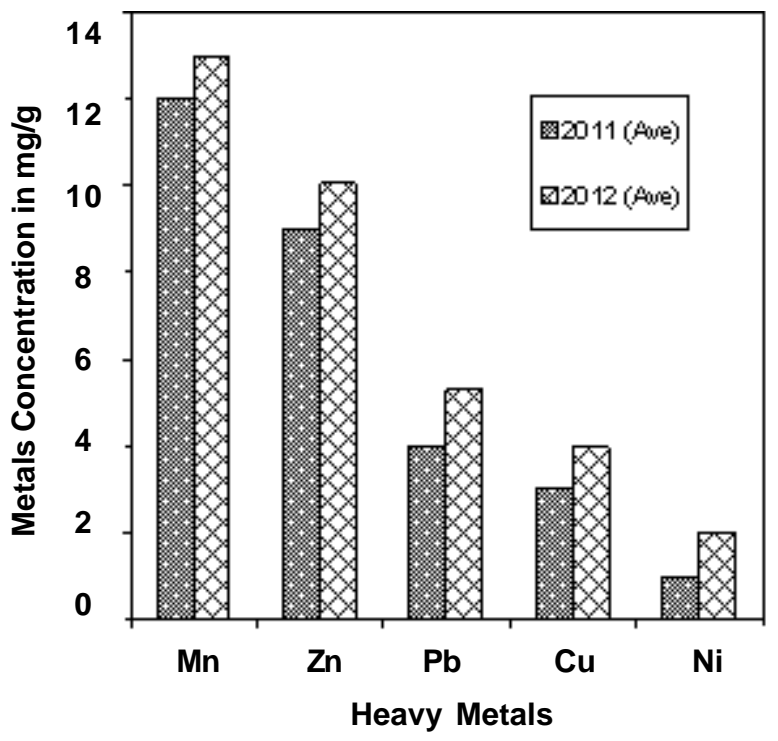

Fig . 4: Comparison of average content of heavy metals in dust fall during 2011 and 2012

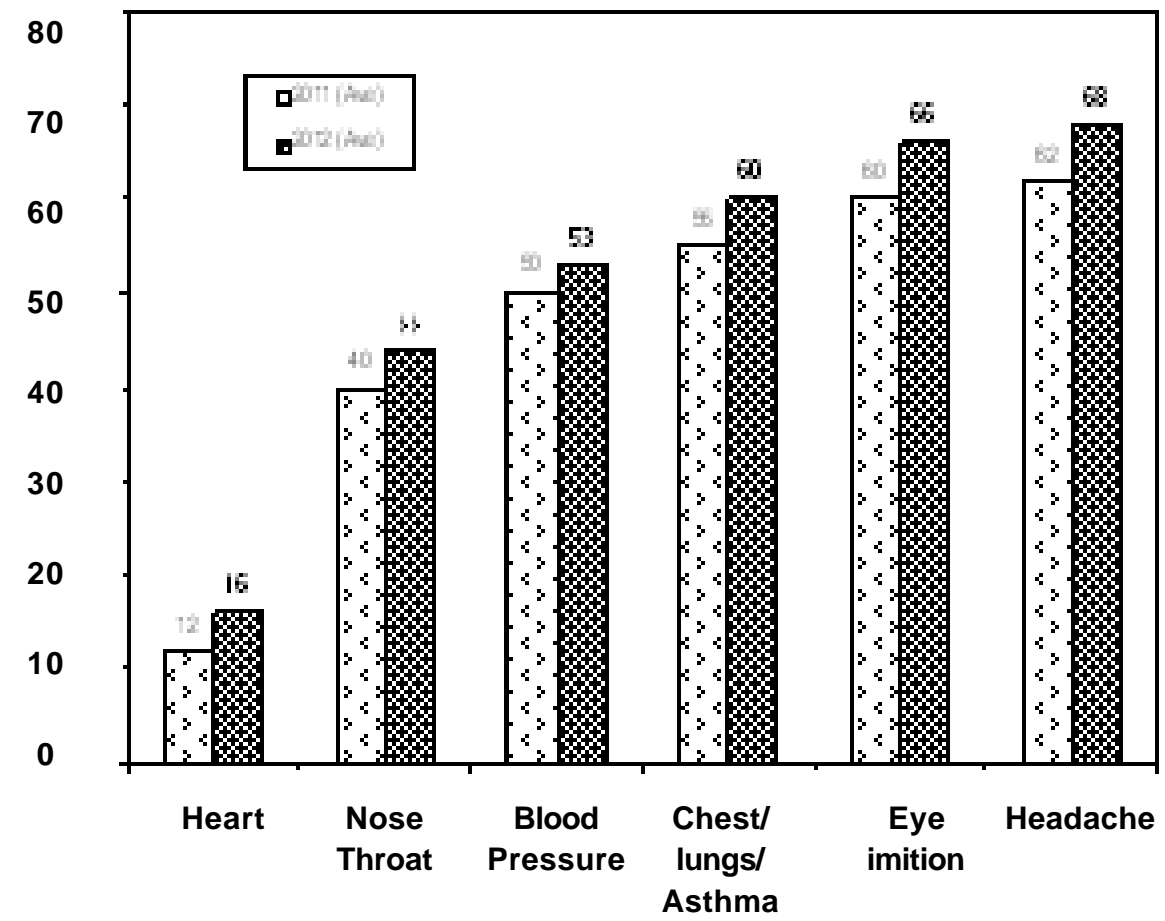

Fig . 5:Percentage of the people suffering in different diseased during two consecutive year (2011-2012) 
Where as Waidhan bus stop standing with the highest dust fall and Shakti nager road with the lowest (fig. 1). The higher amount of dust fall at Waidhan bus stop was attributed to the high traffic mobility and population density as it is the busiest road of the city, other factors like construction of road, lack of proper arrangement of the vehicles parking, presence of goods stores, and lack of awareness about air pollution and dusty weather condition of the area are adding more dust pollution to the atmosphere of Singrauli. Due to above facts and figure the site was expected to be the most polluted area as compared to the other site. The finding of (Beg. et al., 1987 and Khan et al., 2002) also supported the above mentioned facts.

Moreover average rate of dust fall on all the locations during 2011 and 2012 was found to be 41.72 and $44.79 \mathrm{~g} / \mathrm{m}^{2} /$ month respectively (fig. 2) which might be due to climate changes, global warming, increasing population and increasing rate of bomb blast and fires in the city or increasing rate of traffic density unfortunately, these aspects are closely associated with the hazards to the environment and human health caused by transport particularly, road transport, the above views were also supported by (Dora and Phillip, 2000).

Furthermore the rate of dust fall positively correlated with the number of vehicles passing along different road of the city as the number of vehicle increased the rate of dust fall also increased (fig. 3). The lowest rate of dust fall at Shakti nagar road, might be due to the slowest and lowest moving traffic, because Shakti nagar is the main market of Singrauli due to rush of pedestrians peoples walk and shop on the road due to which no clear space for driving is available.

The average content of $\mathrm{Mn}$ in traffic generated dust collected during 2011-2012 was found 10.9 to $14.7 \mathrm{mg} / \mathrm{g}$. with Waidhan market road the largest content and Waidhan bus stop road showing the least.

The mean value of $\mathrm{Mn}$ in dust fall were observed higher than the critical level of $5 \mathrm{mg} / \mathrm{g}$. (Rhue and Kidder, 1983). The overall average concentration of $\mathrm{Mn}$ was found to be $12.3 \mathrm{mg} / \mathrm{g}$. which were the highest among all the observed metals (table 2). This spurious variation of $\mathrm{Mn}$ is difficult to explain but it might be due to contamination of road dust/soil of the area. The Copper metal was found highest at Waidhan market road sample and lowest at Waidhan bus stop (table 2).

The toxic metal $\mathrm{Pb}$ was present highest at Shakti nagar road sample lowest at waidhan bus stop road. The high concentration of $\mathrm{Pb}$ (lead) was correlated with high traffic density. Ni concentration was found highest at Shakti nagar road lowest at Morba Chauk near bus stop. Zn was found highest at Shakti nagar road $(8.8 \mathrm{mg} / \mathrm{g})$ lowest $(10.3 \mathrm{mg} / \mathrm{g})$ at Morba Chauk near bus stop; its value shows an inverse relationship with traffic density. The level of all the investigated metals were found high during 2012 with respect to 2011 (fig. 4).

The level of all these metals except $\mathrm{Ni}$ remains higher at all the location. The positive correlation of some metals with number of vehicle may indicate the exhaust of the vehicles as the emanating sources. However with the exception of lead $(\mathrm{Pb})$ other metals are not normally found in gasoline and disease, the sources of these metals are both mobile and stationary. For determining health impact of dust fall, questionnaires survey indicated that the percentage of people suffering form cardiac disease was $12 \%$ and $16 \%$, ENT disease $40 \%$ and $44 \%$, blood pressure $50 \%$ and $53 \%$, pulmonary disease $55 \%$ and $60 \%$, eye irritation $60 \%$ and $66 \%$ and headache $62 \%$ and $68 \%$ during 2011-2012 respectively (fig. 5 ). Total average data taken from different hospitals of Singrauli during 2011 and 2012.

Correlation coefficient between the data's collected from different hospitals and questionnaires about different diseased categories table no. 3 indicated that cardiac patients and ENT patients showed significant relationship while eye irritation case exhibited non-significance relationship. The reported different diseases in the urban area of Singrauli might be due to different factors like, high traffic density, use of disease /petrol oil and emission from tyres are the Maine cause of air pollution particularly dust fall and its heavy metals contamination fig. 5 . 


\section{CONCLUSION}

In this study it has been concluded that atmosphere of the Singrauli city is highly polluted because of high rate of traffic generated dust, it was also noticed that main causes of dust fall pollution are the vehicle movement and winds. Result reported that rate of dust fall significantly increase from 2011 to 2012. Result also exhibited that majority of the people of Singrauli city particularly those who were directly exposed to the dust fall pollutants are badly affected due to traffic generated pollutants and they were mostly suffering from different diseases, this is in agreement with the reports of public health in connection with the degrading air environment of Singrauli.

\section{REFERENCES}

1. Ara. F. Zm. Iqbal and M. S. Qureshi Detemination of heavey metals contaminations of trees and soil due to vehicular emission in Karachi city, Kar Univer. J.Sci. 24(1) 80-84 (1996).

2. Benneth, B. G., Exposure commitment assessment of environmental pollutions. monitoring and assessment Research centre, London, Brit. Med. Journal (1) 454458, (1981).

3. Bruneckreef, B. Air Pollution from lorry traffic and lung infection in children living near motorways epidemiology ;8(3) 298-303, (1997).

4. Cacciola R. R., M. Sarva and R. P. Olosa , Adverse respiratory effect and allergic susceptibility in relation to particulate air pollution, Flirting with disaster Allergy, 57, 281-286, (2002).
5. Cheng, M. F. Scho, H F. Chiu, T. N. Wu, P.S. Chen and C. Y. Yong, Consequences of exposure to Asian dust storm event on daily pneumonia hospital admission in Taipei, Taiwan, Journal of Toxical, Environ, Health A., 71 (19) 1295-98, (2008).

6. Derbyshire, E., Natural miner genie dust and human health, Ambio 36, 73-77, (2007).

7. Farid, U. K., B. Shakila, G.G. Ejaz and M. Ahmad, Air pollution in Peshawar, Pak J. Sci. Ind. Res. (95), 1-6, (2002).

8. Livingstone, A. E. et al., People living near inner city main road have more asthma needing treatment, case control study, British Medical Journal, 312, 676-677, (1996).

9. Hock, G. B. Et. al., Association between mortality and indicators of traffic related air pollution in the Netherlands, Journal of Lancet, 360, 1203-1219, (2002). 